\title{
Soil Stabilization using Geosynthetic Material (Steel Fibres)
}

\author{
D.V.S. K Chaitanya, P. Neeharika
}

\begin{abstract}
Soil stabilization is the process which involves enhancing the physical properties of the soil in order to improve its strength, durability etc. by blending or mixing with additives. The different types of method used for soil stabilization are: Soil stabilization with cement, Soil stabilization with lime, Soil stabilization using bitumen, Chemical stabilization and a new emerging technology of stabilization by Geo textiles and Geo synthetic fibers. In this study, we are making use of Steel fibers as geo synthetic material for stabilization of soil. With the introduction of Steel fibers to the soil the CBR values will improve and thickness of pavement layer also gets reduced. It also reduces the intensity of stress on subgrade. Steel fibers is such a geosynthetic material which is effectively accessible, ecofriendly and furthermore savvy. With the use of soil adjustment strategy in development the general expense gets diminished when contrasted with the normal technique for development. The Highway Research Board (HRB) order of the dirt strata like dark cotton soil and sedu soil is finished utilizing appropriate examining system, for example, Core Cutter Method. To decide the attributes like Grading by Sieve Analysis, Atterbergs Limits i.e Liquid farthest point utilizing Cone Penetration Method and Casagrande Method, Plastic breaking point by rolling the example to $3 \mathrm{~mm}$ breadth string, Shrinkage limit utilizing Shrinkage mechanical assembly, Optimum Moisture Content and Maximum Dry Density utilizing Standard Proctor Test and furthermore California Bearing Ratio by leading CBR test.
\end{abstract}

The pavement thickness was designed using pavement design catalogues published by IRC SP:20-2002. The estimation for the road is done by considering the item such as Jungle Cutting, Earthwork Excavation for Roadway and Drains, compacting and grading etc., as per SR 2016-17, PW, $P$ and IWT circle Dharwad and suggestion of specification for the mixture of Steel fibers as Geo Synthetic material for stabilization using CBR value by $C B R$ Test and Shear strength using Unconfined Compression Test.

The different tests were conducted in order to determine the different characteristics and properties of the black cotton soil and obtained with following results. The liquid limit of the soil with addition of Steel fibers was found to be decreasing when compared to liquid limit of soil alone.

The plastic furthest reaches of the dirt diminished with the expansion of filaments. The shrinkage furthest reaches of the dirt was expanded with increment in strands. The MDD of the dirt with expansion of Steel filaments by weight of soil is observed to increment upto $0.75 \%$ after that it diminishes and the comparing OMC is diminished with expansion of strands. The shear quality of soil diminished significantly with expansion of strands. The CBR estimation of the dirt expanded significantly. The distinctive tests were led so as to decide the diverse qualities and properties of the sedu soil and acquired with following outcomes. The fluid furthest reaches of the dirt alone was observed to be 36.5\%. The MDD of the dirt with expansion of $0.25 \%, 0.5 \%$ Steel strands by

Revised Manuscript Received on April 12, 2019.

D.V.S. K Chaitanya, Department of Civil Engineering, A.N.U College of Engineering \&Technology, AcharyaNagarjuna University, Guntur, A.P ,India.

P. Neeharika, Department of Civil Engineering, A.N.U College of Engineering \&Technology, AcharyaNagarjuna University.Guntur, A.P India. weight of soil is observed to be diminished by $0.83 \%$ and $0.75 \%$, $1.0 \%$ Steel filaments by weight of soil is observed to be expanded by $0.11 \%$ and $16.98 \%$ separately and the relating $\mathrm{OMC}$ is diminished by $15.62 \%, 21.87 \%$ and $33.75 \%$ individually. The shear quality of the dirt with the expansion of $0.25 \%, 0.5 \%$, $0.75 \%$ and $1 \%$ of Steel strands is observed to be diminished by $38.57 \%$, $38.57 \%$, $35.25 \%$ and $5.85 \%$.

The CBR estimation of the dirt with expansion of $0.25 \%, 0.5 \%$, $0.75 \%$ and $1.0 \%$, Steel filaments by weight of soil is observed to be expanded. From the restricted research center investigation directed we reasoned that the $0.75 \%$ of Steel fiber can generously improve the properties of Black cotton soil. Furthermore, in this way $0.75 \%$ of Steel fiber is the ideal fiber content for dark cotton soil.

The design thickness of flexible pavement before stabilization is obtained as $450 \mathrm{~mm}$ and after stabilization is obtained as 250mm.The estimated cost for constructing flexible pavement before stabilization of soil is obtained as $4018050 \mathrm{Rs} / \mathrm{Km}$ and after stabilization of soil is obtained as 3721894Rs/Km. The estimated cost after stabilization is found to be decreased by $7.37 \%$

\section{INTRODUCTION}

Soil adjustment is the procedure which includes upgrading the physical properties of the dirt so as to improve its quality, strength and so on by mixing or blending it with added substances. The distinctive kinds of strategies utilized for soil adjustment are: Soil adjustment utilizing concrete, Soil adjustment utilizing lime, Soil adjustment utilizing bitumen, Chemical adjustment and another rising innovation of adjustment that is adjustment of soil by utilizing Geo materials and Geo engineered strands.

Geo synthetics are engineered items produced using different sorts of polymers which might be either Woven or Non-Woven. These are utilized to upgrade the attributes of soil and have given a functional method for developing structural building structures monetarily.

In this investigation, we are making utilization of Steel filaments as geo engineered material for adjustment of soil. With the acquaintance of Steel filaments with the dirt the CBR esteems may improve and thickness of asphalt layer additionally may get decreased. It might likewise decrease the power of weight on subgrade. Steel filaments is such a geosynthetic material which is effectively accessible, ecoaccommodating and furthermore financially savvy. With the utilization of soil adjustment procedure in development process the general expense may get diminished when contrasted with the common technique for development.

Objectives of the project work

To categorize the clayey soil namely black cotton soil and

Published By: 
sedu soil as per Highway Research Board classification.

To analyze the characteristics of soil for different concentrations of Geo synthetic material (Steel fibers) mixed with it.

The design of flexible pavement without Geo synthetic material and with the optimum concentration of the geo synthetic material mixed with the above soil as per IRC SP:20-2002.

\section{LITERATURE REVIEW}

\subsection{Stabilization of Black Cotton Soil using Lime and} Geogrid $^{[2]}$ (2009)

Sujitkawade et al., studied the effect of Lime and geogrid on the properties of the soil.Their main objectives was to determine the properties of the soil before and after the addition of lime and geogrid to it. The different tests they conducted were natural moisture content determination, specific gravity, Atterbergs limits, Compaction test, Compressive Strength test. After studying and conducting the entire above test, the optimum lime content was found to be $15 \%$ and they concluded that there was a substantial increase in the compressive strength of the soil.

\subsection{Geotextiles: An Overview ${ }^{[3]}$ (2010)}

AyushMithal and Dr. ShalinuShukla studied the effectiveness of use of geotextiles as reinforcement material for stabilization of soil for different engineering works. Their objectives were to study and introduce the properties of Geotextiles (such as Physical property, Mechanical property, Hydraulic property, Endurance property and Durability property), Fibers of Geotextiles, (they are natural and synthetic fibers), Types of Geotextiles, functions of Geotextiles, application of geotextiles and impact of geotextiles on environment. They have concluded that, due to the versatility of functions of geotextiles they can be used in many important civil engineering works. The use of geotextiles not only reduces construction cost but also reduce maintenance cost.

2.3 Improvement in CBR value of Black cotton soil by stabilizing it with vitrified polish waste ${ }^{[4]}(2011)$

Vegulla .Raghudeep et al ., studied the effect of vitrified polish waste on the properties of the soil. Their objective was to check the reduction in pavement thickness due to increase in CBR because of addition of polish waste. They conducted the tests like Grain size distribution, Atterbegs limits, Compaction tests and CBR tests on soil alone and with addition of vitrified polish waste. They conducted that $10 \%$ addition of vitrified polish waste resulted in substantial increase in CBR value and significant reduction in pavements thickness was reported.

\section{ANALYSIS OF DATA}

\subsection{Wet Sieve Analysis}

Wet sieve analysis of Black cotton soil collected from near was carried out in order to classify the soil. The following observations were made: Sample taken [passing $4.75 \mathrm{~mm}$ sieve before washing] $=200 \mathrm{~g}$

Sample retained on $0.075 \mathrm{~mm}$ sieve after washing and drying $=115 \mathrm{~g}$
Sample passed through $0.075 \mathrm{~mm}$ sieve after washing $=$ $85 \mathrm{~g}, 42.5 \%$

Table 3.1: Sieve analysis of Black cotton soil

\begin{tabular}{|l|l|l|l|l|l|l|}
\hline Sl.No. & $\begin{array}{l}\text { IS sieve } \\
\text { size }\end{array}$ & $\begin{array}{l}\text { Particle } \\
\text { size (D) } \\
\mathbf{M m}\end{array}$ & $\begin{array}{l}\text { Mass of } \\
\text { soil } \\
\text { retained } \\
(\mathbf{M}) \mathbf{g}\end{array}$ & $\begin{array}{l}\text { \% Mass of } \\
\text { retained } \\
\mathbf{M} / \mathbf{M}) * \mathbf{1 0 0}\end{array}$ & $\begin{array}{l}\text { Cumulative } \\
\text { \% retained, } \\
\mathbf{C}\end{array}$ & $\begin{array}{l}\text { Cumulative } \\
\text { \% Fine } \\
\mathbf{N = 1 0 0 - C}\end{array}$ \\
\hline 1 & 2.000 & 2.000 & 0 & 0.00 & 0.00 & 100.00 \\
\hline 2 & 1.000 & 1.000 & 06 & 05.22 & 5.22 & 94.78 \\
\hline 3 & 0.600 & 0.600 & 37 & 32.17 & 37.39 & 62.61 \\
\hline 4 & 0.425 & 0.425 & 09 & 07.83 & 45.22 & 54.78 \\
\hline 5 & 0.300 & 0.300 & 15 & 13.04 & 58.26 & 41.74 \\
\hline 6 & 0.212 & 0.212 & 17 & 14.78 & 73.04 & 26.96 \\
\hline 7 & 0.150 & 0.150 & 00 & 0.00 & 73.04 & 26.96 \\
\hline 8 & 0.075 & 0.075 & 29 & 25.22 & 98.26 & 01.74 \\
\hline 9 & Pan & 0 & 0 & 0.00 & 98.26 & 01.74 \\
\hline
\end{tabular}

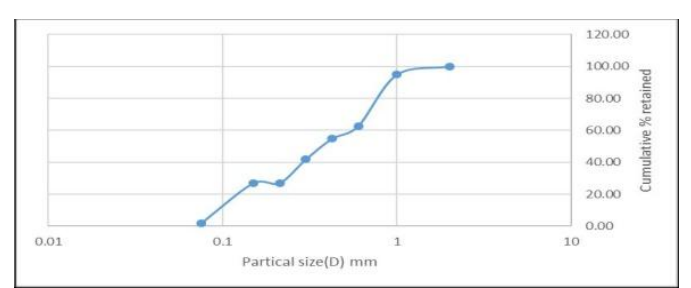

Figure 3.1: Particle size distribution curve of Black cotton soil

Liquid Limit Test

3.3.1 Cone Penetration Test

Sample Taken [passing through $=425 \mu$ ] $=150 \mathrm{~g}$

Table 3.2: Liquid limit test on Black cotton soil using cone penetration method

\begin{tabular}{|c|c|c|c|}
\hline Trial No. & $\begin{array}{c}\text { Water } \\
\text { Content, \% }\end{array}$ & $\begin{array}{l}\text { Water } \\
\text { Amoun } \\
\mathbf{t}, \mathbf{m l}\end{array}$ & $\begin{array}{c}\text { Penetration, } \\
\mathbf{m m}\end{array}$ \\
\hline 1 & 50 & 75 & 16 \\
\hline 2 & 55 & 82.5 & 17 \\
\hline 3 & 60 & 90 & 20 \\
\hline 4 & 65 & 97.5 & 35 \\
\hline 5 & 70 & 105 & 44 \\
\hline
\end{tabular}

Liquid limit as obtained from graph $=60 \%$

(Corresponding to $20 \mathrm{~mm}$ penetration)

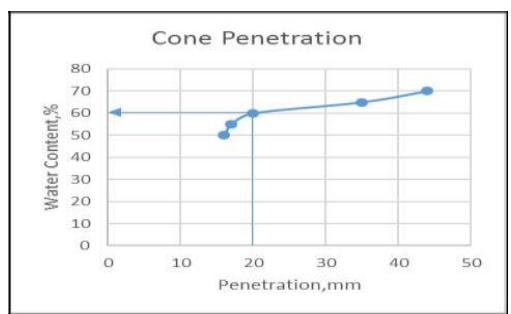

Figure 3.2: Liquid Limit curve (Cone Penetration)

Published By:

Blue Eyes Intelligence Engineering

\& Sciences Publication 


\subsection{Plastic Limit test:}

Table 3.3: Plastic limit test on Black cotton soil

\begin{tabular}{|l|l|}
\hline Trial Number & 1 \\
\hline Container No. & $\mathrm{GT}-19$ \\
\hline $\begin{array}{l}\text { Mass of empty container, } \\
\mathrm{M}_{1} \mathrm{~g}\end{array}$ & 32.15 \\
\hline $\begin{array}{l}\text { Mass of container }+ \text { wet } \\
\text { soil, } \mathrm{M}_{2} \mathrm{~g}\end{array}$ & 47.15 \\
\hline $\begin{array}{l}\text { Mass of container }+\mathrm{dry} \\
\text { soil, } \mathrm{M}_{3} \mathrm{~g}\end{array}$ & 44.50 \\
\hline $\begin{array}{l}\text { Mass of water }=\mathrm{M}_{\mathrm{w}}=\mathrm{M}_{2^{-}} \\
\mathrm{M}_{3}\end{array}$ & 02.65 \\
\hline $\begin{array}{l}\text { Mass of dry soil }=\mathrm{M}_{\mathrm{d}}=\mathrm{M}_{3^{-}} \\
\mathrm{M}_{1} \mathrm{~g}\end{array}$ & 12.35 \\
\hline $\begin{array}{l}\text { Plastic Limit, } \% \\
\mathrm{~W}_{\mathrm{p}}=\left(\mathrm{M}_{\mathrm{w}} / \mathrm{M}_{\mathrm{d}}\right) * 100\end{array}$ & 21.46 \\
\hline
\end{tabular}

3.3 Plasticity Index

Soil Sample - 1

$\mathrm{Ip}=\mathrm{WL}-\mathrm{WP}=60-21.46=\mathbf{3 8 . 3 6 \%}$

\section{RESULT AND DISCUSSION}

\section{4..1. General}

\subsection{Atterbergs Limit}

\subsection{1. $\quad$ Liquid limit}

1. The liquid limit of the soil alone was found to be $60 \%$

2. The liquid limit of the soil with addition of $0.25 \%$, $0.5 \%, 0.75 \%$ and $1.0 \%$, by weight of soil is found to be $39.2 \%, 39.7 \%, 42.0 \%$ and $42.3 \%$ respectively.

3. The liquid limit of the soil with addition of $0.25 \%$, $0.5 \%, 0.75 \%$ and $1.0 \%$, Steel fibers is found to be decreased by $34.66 \%, 33.83 \%, 30.0 \%$ and $29.5 \%$ respectively, when compared to liquid limit of soil alone.

\subsubsection{Plastic limit}

1. The plastic limit of the soil alone was found to be $21.46 \%$

2. The plastic limit of the soil with addition of $0.25 \%$, $0.5 \%, 0.75 \%$ and $1.0 \%$, Steel fibers by weight of soil is found to be $22.27 \%, 33.33 \%, 35.59 \%$ and $37.50 \%$ respectively.

3. The plastic limit of the soil with addition of $0.25 \%$, $0.5 \%, 0.75 \%$ and $1.0 \%$, Steel fibers is found to be decreased by $21.3 \%, 43.5 \%, 51.8 \%$ and $58.8 \%$ respectively, when compared to plastic limit of soil alone.

\subsubsection{Plasticity Index}

1. The plasticity index of the soil alone was found to be $38.54 \%$.
2. The plasticity index of the soil with addition of $0.25 \%$, $0.5 \%, 0.75 \%$ and $1.0 \%$, Steel fibers by weight of soil is found to be $11.93 \%, 6.37 \%, 6.41 \%$ and $4.8 \%$ respectively.

3. The plasticity index of the soil with the addition of $0.25 \%, 0.5 \%, 0.75 \%$ and $1 \%$ of Steel fibers is found to be decreased by $69 \%, 84.47 \%, 83.36 \%$ and $87.54 \%$.

\subsubsection{Shrinkage limit}

1. The shrinkage limit of the soil alone was found to be $23.309 \%$

2. The shrinkage limit of the soil with addition of $0.25 \%$, $0.5 \%, 0.75 \%$ and $1.0 \%$, Steel fibers by weight of soil is found to be $16.471 \%, 15.876 \%, 8.043 \%$ and $5.826 \%$ respectively.

3. The shrinkage limit of the soil with the addition of $0.25 \%, 0.5 \%, 0.75 \%$ and $1 \%$ of Steel fibers is found to be decreased by $29.31 \%, 31.88 \%, 65.49 \%$ and $75 \%$.

\subsection{Standard Proctor Test}

- The optimum moisture content (OMC) and maximum dry density (MDD) of soil alone was found to be $21.4 \%$ and $1.378 \mathrm{~g} / \mathrm{cc}$ respectively.

- The MDD of the soil with addition of $0.25 \%, 0.5 \%$, $0.75 \%$ and $1.0 \%$, Steel fibers by weight of soil is found to be $1.401 \mathrm{~g} / \mathrm{cc}, 1.425 \mathrm{~g} / \mathrm{cc}, 1.565 \mathrm{~g} / \mathrm{cc}$ and $1.378 \mathrm{~g} / \mathrm{cc}$ respectively and the corresponding OMC is found to be $20.1 \%, 19 \%, 17 \%$ and $16 \%$ respectively.

- The MDD of the soil with addition of $0.25 \%, 0.5 \%$, $0.75 \%$ and $1.0 \%$, Steel fibers by weight of soil is found to be increased by $1.6 \%, 3.4 \%, 13.5 \%$ and $0 \%$ respectively and the corresponding $\mathrm{OMC}$ is decreased by $6 \%, 11.2 \%, 20.56 \%$ and $21.02 \%$ respectively.

\subsection{Unconfined Compression Test}

- The shear strength of soil alone was found to be 1.27MPa.

- The shear strength of the soil with addition of $0.25 \%$, $0.5 \%, 0.75 \%$ and $1.0 \%$, Steel fibers by weight of soil is found to be $1.687,1.838,1.868$ and $1.989 \%$ respectively.

- The shear strength of the soil with the addition of $0.25 \%, 0.5 \%, 0.75 \%$ and $1 \%$ of Steel fibers is found to be decreased by $32.83 \%, 44.72 \%, 47.08$ and $56.61 \%$.

\subsection{California Bearing Ratio (CBR) Test}

- The CBR value of soil alone was found to be $1.82 \%$

- The CBR value of the soil with addition of $0.25 \%$, $0.5 \%, 0.75 \%$ and $1.0 \%$, Steelfibers by weight of soil is found to be $3.49 \%, 3.96 \%, 5.41 \%$ and $3.96 \%$ respectively.

- The CBR value of the soil with addition of $0.25 \%$, $0.5 \%, 0.75 \%$ and $1.0 \%$, Steel fibers by weight of soil is found to be increased by $91.75 \%, 117.5 \%, 197.25 \%$ and $117.5 \%$ respectively.

4.6 Atterbergs Limit (sedu soil) 


\subsubsection{Liquid limit}

- The liquid limit of the soil alone was found to be $36.5 \%$

\subsection{Standard proctor test}

- The optimum moisture content (OMC) and maximum dry density (MDD) of soil alone was found to be $16 \%$ and $1.802 \mathrm{~g} / \mathrm{cc}$ respectively

- The MDD of the soil with addition of $0.25 \%, 0.5 \%$, $0.75 \%$ and $1.0 \%$, Steel fibers by weight of soil is found to be $1.788 \mathrm{~g} / \mathrm{cc}, 1.788 \mathrm{~g} / \mathrm{cc}, 1.804 \mathrm{~g} / \mathrm{cc}$ and $2.108 \mathrm{~g} / \mathrm{cc}$ respectively and the corresponding OMC is found to be $13.5 \%, 13.5 \%, 12.5 \%$ and $10.6 \%$ respectively.

- The MDD of the soil with addition of $0.25 \%, 0.5 \%$ Steel fibers by weight of soil is found to be decreased by $0.83 \%$ and $0.75 \%, 1.0 \%$ steel fibers by weight of soil is found to be increased by $0.11 \%$ and $16.98 \%$ respectively and the corresponding OMC is decreased by $15.62 \%, 21.87 \%$ and $33.75 \%$ respectively.

\subsection{Unconfined Compression Test:}

- The shear strength of soil alone was found to be 1.024 $\mathrm{MPa}$.

- The shear strength of the soil with addition of $0.25 \%$, $0.5 \%, 0.75 \%$ and $1.0 \%$, Steel fibers by weight of soil is found to be $0.629,0.629,0.663$ and $0.964 \%$ respectively.

- The shear strength of the soil with the addition of $0.25 \%, 0.5 \%, 0.75 \%$ and $1 \%$ of Steel fibers is found to be decreasedby $38.57 \%, 38.57 \%, 35.25 \%$ and $5.85 \%$.

\subsection{California Bearing Ratio (CBR) Test}

- The CBR value of soil alone was found to be $4.28 \%$

- The CBR value of the soil with addition of $0.25 \%$, $0.5 \%, 0.75 \%$ and $1.0 \%$, Steel fibers by weight of soil is found to be $27.74 \%, 29.20 \%, 27.74 \%$ and $44.77 \%$ respectively.

- The CBR value of the soil with addition of $0.25 \%$, $0.5 \%, 0.75 \%$ and $1.0 \%$, Steel fibers by weight of soil is found to be increasedThe design thickness of flexible pavement before stabilization is obtained as $450 \mathrm{~mm}$.

- The design thickness of flexible pavement after stabilization is obtained as $250 \mathrm{~mm}$. The estimated cost for constructing flexible pavement before stabilization of soil isobtained as $4018050 \mathrm{Rs} / \mathrm{Km} 3$

- The estimated cost for constructing flexible pavement after stabilization of soil is obtainedas $3721894 \mathrm{Rs} / \mathrm{Km}$

\section{CONCLUSIONS}

On the basis of present experimental study, the following conclusions are drawn

1. According to the Highway Research Board classification, the black cotton soil sample has been categorized as A-7-6 (4.549)

2. There is substantial increase in MDD with increase in addition of fibers upto $0.75 \%$ by weight beyond which it decreased.

3. There is substantial decrease in OMC with increase in addition of fibers.
4. In unconfined compression test it was observed that the shear strength of the soil has increased with the increase in percentage of Steel fibers, when compared to that of shear strength of soil tested without fiber.

5. The shear strength of the soil is maximum when $1 \%($ by weight of soil) of Steel fibers is added to it. Hence in order to obtain higher shear resistance $1 \%$ of fibers (by weight of soil) can be considered as the optimum fiber content.

6. The California bearing ratio (CBR) of the soil alone is obtained as $1.82 \%$ and it increased to $5.41 \%$ after stabilizing it with optimum percentage of Steel fibers.

7. The percentage increase in CBR value after stabilizing it with optimum percentage of fibers is $197.25 \%$.

8. In the case of sedu soil there is substantial increase in MDD with increase in addition of fibers.

9. In unconfined compression test it was observed that the shear strength of the soil has decreased with the increase in percentage of Steel fibers, when compared to that of shear strength of soil tested without fiber.

10. The California bearing ratio (CBR) of the soil alone is obtained as $4.28 \%$ and there substantial increase in CBR value with addition of fibres.

\section{REFERENCES}

1. SujitKawade, MahendraMapari, Mr.ShreedharSharana" Stabilization of Black cotton soil with lime and Geo-grid"

2. Ayush Mittal, ShalineeShukla "GEOTEXTILE: AN OVERVIEW"

3. VegullaRaghudeep, "Improvement in CBR value of black cotton soil by stabilization it with vitrified polish waste"

4. HarshitaBairagi "International journal of engineering sciences and research technology"

5. VikasRameshraoKulkarni "Experimental study of stabilization of B.C. soil by using Slag and Glass fibers"

6. John Paul V. Antony Rachel Sneha M. " Effect of random inclusion of Steelfibers on strength behaviour of flyash treated black cotton soil"

7. I.S: 2720 (Part I)-1983 : "Indian standard for preparation of dry soil samples for various tests", Bureau of Indian Standards Publications, New Delhi.

8. I.S: 2720 (Part IV)-1985 : "Indian standard for grain size analysis", Bureau of IndianStandards Publications, New Delhi.

9. I.S: 2720 (Part V)-1985 : Indian standard for determination of liquid limit and plastic limit", Bureau of Indian Standards Publications, New Delhi.

10. I.S: 2720 (Part IV)-1985 : "Indian standard for grain size analysis", Bureau of IndianStandards Publications, New Delhi.

11. I.S: 2720 (Part V)-1985 : Indian standard for determination of liquid limit and plastic limit”, Bureau of Indian Standards Publications, New Delhi.

12. I.S: 2720 (Part VII)-1980 : "Indian standard for determination of water content- Dry density relationship using light compaction", Bureau of Indian Standards Publications, New Delhi. 